\title{
* Psychological Concerns and Effects on Immune Responses amidst Covid-19 Pandemic
}

\author{
Sundas Ali $^{1}$, Javera Tariq ${ }^{2}$
}

1,2 Pakistan Institute of Medical Sciences, Islamabad, Pakistan

$\mathrm{U}$ ndoubtedly, mental and physical well-being has been strongly linked with each other and proven connections exist between the two facets even after controlling for the confounding factors (1).

In the context of these findings, the emergence of Severe Acute Respiratory Syndrome Coronavirus 2 (SARS-CoV-2) and its declaration as a pandemic and global public health concern by the World Health Organization, $(2,3)$ there has been an enormous degree of emotional and psychological crisis at the community level.

As COVID-19 is a novel disease having a devastating, widespread and swift global spread, unquestionably, an intense anxiety, confusion and dread is prevalent among the general public. Looking at the various whys and wherefores of this trepidation, social stigma associated with the disease, the constant discussion on the pandemic status on electronic, print and social media, with reports of increasing number of cases and deaths, bombardment of myths along with false news are some of the major factors. Resultantly, people are feeling more and more emotionally exhausted and vulnerable (4). Among the health care professionals, contributory elements include a shortage of personal protective equipment, higher risk of contact, moral predicaments, extreme job assignments, commitments, being over-concerned about themselves and their families, a rapidly evolving work environment, and guidelines which majority of them is unfamiliar with $(4,5)$. Other emotional stressors comprise non-availability of specific treatment or vaccine for COVID-19 infection.
Moreover, in conjunction with the economic and financial stresses, shortage of resources and daily commodities further increase the trend of panic buying. Among the masses, the opportunities to vent out their misery have been limited due to the worldover lockdown state as societal shifts like social distancing, isolation, self-quarantine and travel bans pose a significant distress in the form of anxiety, anguish and symptoms of post-traumatic stress (4).

The strong effects of this level of mental commotion on the bodily health have been well defined in literature as early as the 3rd century B.C, during which the work by the Greek philosophers, Aristotle and Socrates proposed attentive discourse regarding the deep-rooted connections between psychological and physiological processes. Since then, the negative somatic effects related with psychological ill-health such as anxiety and depression have been well documented. In view of this finding, a current paradigm shift in the arena of public health and medical expertise has expanded its emphasis by pinpointing and considering those protective psychological properties that may channelize the preservation or promotion of greater physical health and endurance. (6)

The central nervous system, endocrine and immune systems are intricately connected, with stress and emotional disturbance leading to deregulation of immune responses. Firstly, chronic stressors can suppress the innate and acquired immunity by causing imbalance of the type 1 /type 2 cytokine response, thereby overriding the immune-protective cells.(7) Secondly, the immunosuppressive nature of 


\section{Psychological Concerns and Effects on Immune Responses amidst Covid-19 Pandemic}

chronic distress can be explained by sympathetic fibers, releasing substances that bind to lymphocytes and influencing immune responses such as diminished cytotoxicity of natural killer cells, suppressed proliferative rate of lymphocytes and dampened responses of active immunization. (8)

Considering this powerful association between stress and weakened immune reactions of this nature, the heightened occurrence of infectious and malignant diseases reported among those chronically stressed persons cannot be overemphasized. (8)

The link between psychological strain and vulnerability to the common cold infection has long been acknowledged. Isolation and seclusion, as is the case during this pandemic era, are another welldocumented risk factor for detrimental physical wellbeing. In one study, after a viral challenge, cold symptoms were more severe among the lonely individuals (LeRoy et al. 2017). Similarly, a metaanalysis of 13 studies came to a conclusion that the humoral response to influenza vaccination was $41 \%$ of psychologically strained individuals versus 59\% of less-strained individuals. (Pedersen et al. 2009) Furthermore, studies in adolescents and adults have confirmed that negative emotions, in the form of depression or anxiety modify the antibody and cellular responses to antiviral immunizations, weakening the immune responses. Seeing it from another angle, various mind-body therapeutic interventions, including meditation, massage intervention and Yoga, have been shown to have a positive effect on generating virus-specific responses to vaccines and overall immunity in a meta-analysis based on 34 studies (Morgan et al. 2014). (7)

Few recommendations that can be offered to break this negative connection include provision of psycho-education and coping strategies to general population and specifically to patients visiting hospital for consultation. Secondly, governmental health authorities need to disseminate accurate information to reduce the influence of rumors. Thirdly, online Cognitive Behavioral Therapy interventions should be in place to minimize the risk of exposure and fourthly, adequate personal hygiene infrastructure and equipment be ensured for the healthcare professionals as well as to the community as needed. $(9,10)$

\section{References}

1. Ohrnberger J, Fichera E, Sutton M. The relationship between physical and mental health: A mediation analysis. Soc Sci Med. 2017;195:42-9.

2. Hartley DM, Perencevich EN. Public Health Interventions for COVID-19: Emerging Evidence and Implications for an Evolving Public Health Crisis. JAMA. Published online April 10, 2020. doi:10.1001/jama.2020.5910

3. McMichael TM, Currie DW, Clark S, Pogosjans S, Kay M, Schwartz NG, et al. Epidemiology of Covid-19 in a Long-Term Care Facility in King County, Washington. N Engl J Med. 2020:1-7.

4. Roy D, Tripathy S, Kar SK, Sharma N, Verma SK, Kaushal V. Study of knowledge, attitude, anxiety \& perceived mental healthcare need in Indian population during COVID-19 pandemic.. Asian J Psychiatr. 2020;102083.

5. Shanafelt T, Ripp J, Trockel M. Understanding and Addressing Sources of Anxiety Among Health Care Professionals During the COVID-19 Pandemic. JAMA. Published online April 07, 2020. doi:10.1001/jama.2020.5893

6. Hernandez R, Bassett SM, Boughton SW, Schuette SA, Shiu EW, Moskowitz JT. Psychological Well-Being and Physical Health: Associations, Mechanisms, and Future Directions. Emot Rev. 2018;10(1):18-29.

7. Christian LM, Glaser R. The impact of everyday stressors on the immune system and health. Stress challenges and immunity in space. Springer.2012:31-43.

8. Morey JN, Boggero IA, Scott AB, Segerstrom SC. Current directions in stress and human immune function. Curr Opin Psychol. 2015;5:13-7

9. Dalton L, Rapa E, Stein A. Protecting the psychological health of children through effective communication about COVID-19. Lancet Child Adolesc Heal. 2020;4642(20):19-20.

10. Wang C, Pan R, Wan X, Tan Y, Xu L, Ho CS, Ho RC. Immediate psychological responses and associated factors during the initial stage of the 2019 coronavirus disease (COVID-19) epidemic among the general population in China. Int J Environ Res Public Health. 2020;17(5).E1729. 